\title{
Colangitis bacteriémica en adultos en un hospital general en Chile
}

\author{
Alberto Fica, Verónica Julio, Estefanía Palma, Dannette Guiñez, Lorena Porte, \\ Stephanie Braun y Jeannette Dabanch
}

\section{Bacteremic colangitis in adults in a general hospital in Chile}

Background: Some aspects of bacteremic cholangitis are unknown in Chile. Aim: To gather more information on clinical, microbiological aspects as well as risk factors for ICU admission, recurrence and antimicrobial resistance. Material and Methods: A retrospective research was performed using medical records of adult patients in a general hospital. Results: Between 2006-2012, 22 patients with 29 bacteremic events were identified. Previous cholangitis events were reported by $27.3 \%, 45.5 \%$ had recent admissions and, 50\% had used antimicrobial compounds. Coledocholithiasis was the most common cause of obstruction (45.5\%) followed by cancer (36.4\%). One third developed shock (31\%), the only factor associated with ICU admission (OR 30, p < 0.05). In 24 of the 29 bacteremic events, the biliary tract was intervened (82.8\%) and in $80.8 \%$ during the first 72 hours. Gram negative bacilli were predominant (> 80\%) and some infrequent agents such as Staphylococcus warneri, Shewanella spp. and, Aeromonas spp. were observed. Among enteric gram negative bacilli, 29.2\% presented fluoroquinolone resistance and, 26.1\% resistance to third generation cephalosporins, both associated with previous endoscopic retrograde cholangiography (OR 35 and 16.5, respectively $\mathrm{p}<0.05$ ). A favorable response was observed in $93.1 \%$ of bacteremic events but in $31.8 \%$ of patients cholangitis recurred with or without bacteremia. Recurrence was associated to recent admission (OR 16.5, $\mathrm{p}=0.01$ ) and in all cases occurred before 81 days. In-hospital mortality was $9.1 \%$ $(\mathrm{n}=2)$, but in only one case associated to sepsis. Average length of stay (LOS) was 17.8 days. Conclusions: Early intervention of the biliary tract allows a favorable response in patients affected by bacteremic cholangitis, but this condition use intensive care resources, had a prolonged LOS, a recurrent pattern, and is associated with several bacterial species, some of them resistant.

Key words: Cholangitis, bacteremia, adult, recurrence, survival analysis, neoplasms, cholangiography, microbial drug resistance.

Palabras clave: Colangitis, bacteriemia, adultos, recurrencia, análisis de sobrevida, cáncer, colangiografía, resistencia antimicrobiana.

\section{Introducción}

$\mathrm{L}$ a colangitis aguda, infección de la vía biliar debida a la obstrucción completa o parcial por diferentes causas, incluyendo litiasis biliar, colangitis esclerosante, quistes, divertículos, anormalidades congénitas, pancreatitis, cáncer, oclusión de prótesis de la vía biliar o parásitos, puede asociarse, en ocasiones, a cuadros de bacteriemia o shock séptico ${ }^{1}$. Los cuadros de colangitis aguda bacteriémica son una importante causa de morbilidad y hospitalización, ocasionalmente pueden provocar la muerte pero la información sobre esta patología es fragmentaria en Chile. Por ejemplo, se desconoce cuál es la evolución de estos pacientes o la microbiología asociada y si las bacterias resistentes están presentes en ellos. Tampoco se han identificado factores asociados a una evolución más grave y no hay descripciones sobre los pacientes que tienen recurrencia. Este trabajo fue diseñado para obtener información sobre estas interrogantes y sus objetivos fueron analizar las características clínicas, evolución y factores de riesgo asociados a complicaciones o muerte en una serie de casos de colangitis aguda con bacteriemia asociada en un hospital de referencia.

\section{Pacientes y Métodos}

\section{Diseño y período de estudio}

Estudio retrospectivo, descriptivo, efectuado en el Hospital Militar de Santiago, con pacientes atendidos entre enero del año 2006 y agosto de 2012.

\section{Criterios de inclusión-exclusión}

Pacientes que presentaron fiebre y dolor abdominal, con patología biliar demostrada por imágenes o estudios invasores y con bacteriemia sin otro foco conocido. Se excluyeron pacientes bajo 15 años de edad.
Hospital Militar de Santiago, Santiago, Chile

Departamento de Medicina Servicio de Infectología (AF, VJ, EP, DG, JD). Departamento de Laboratorio Clínico (LP, SB).

Conflicto de interés: ninguno. Financiamiento: ninguno.

Recibido: 28 de agosto de 2012 Aceptado: 28 de noviembre de 2012

Correspondencia a: Alberto Fica Cubillos albertofica@gmail.com 


\section{Captación de casos}

Se identificaron casos mediante el registro de egresos usando los códigos CIE-10 (K83.0) o por el registro personal de uno de los autores (JD).

\section{Variables y factores de riesgo}

La información clínica fue extraída mediante una pauta estructurada desde los registros clínicos en formato de papel o en el nuevo formato digital disponible desde abril de 2012. Se exploraron variables concernientes a la información demográfica, manifestaciones clínicas, etiología de la patología biliar, microbiología, laboratorio, oportunidad y modalidad del tratamiento, terapia antimicrobiana, respuesta a la terapia y condición al alta y a largo plazo, esta última mediante la búsqueda de certificados de defunción de pacientes sin seguimiento post alta hasta agosto de 2012 en la página del Servicio de Registro Civil e Identificación de Chile (http://www.registrocivil. cl). Se exploraron posibles factores asociados al ingreso a UCI, recurrencia de episodios de colangitis, resistencia antimicrobiana y muerte al alta o en el seguimiento.

\section{Definiciones}

En casos de dos o más episodios de bacteriemias en el mismo paciente, éstos fueron considerados como diferentes eventos desde el punto de vista de sus manifestaciones clínicas y microbiológicas. Se definió como recurrencia, los eventos posteriores a la primera bacteriemia y se clasificaron como reinfección si la especie recuperada en hemocultivos fue diferente en cada episodio o como recaída si es que se aisló la misma especie. La oportunidad de la intervención fue definida en ventanas horarias excluyentes desde el ingreso hasta la realización de alguna medida terapéutica sobre la vía biliar o colecciones asociadas. La respuesta terapéutica fue catalogada como cura si la causa de la patología biliar quedó resuelta junto a la mejoría de los síntomas, o como mejoría si el paciente quedó sin una resolución de su patología de base. Sólo se consideraron los estudios de imágenes si éstos se efectuaron en concomitancia al estudio o manejo de la patología biliar y no durante su seguimiento.

\section{Análisis estadístico}

Las variables demográficas, las co-morbilidades, la etiología de la patología biliar y el desenlace al alta o a largo plazo fueron expresadas por número de pacientes. Las manifestaciones clínicas, resultados de laboratorio, datos microbiológicos, manejo, terapia antimicrobiana y resultados clínicos, fueron analizados por evento de bacteriemia. Para facilitar la identificación de potenciales factores de riesgo, las variables continuas fueron convertidas a variables categóricas. La identificación de estos factores se realizó mediante el cálculo de odds ratio (OR) con sus intervalos de confianza. Se aplicaron pruebas no paramétricas en casos con bajo número de datos y un análisis multivariado por regresión logística binaria en caso de identificar varios factores de riesgo asociados a un resultado. En el análisis multivariado se incluyeron aquellas variables que en el análisis univariado hubieran demostrado un nivel de significación $\mathrm{p}<0,10$. Para el seguimiento a largo plazo se aplicaron tablas de sobrevida y el $\log$ rank test para analizar diferencias.

\section{Resultados}

\section{Casos y características de los pacientes}

Un total de 22 pacientes fue identificado entre los años 2006 y 2012. La edad promedio fue de 70,1 años (rango 42-95 años) con un leve predominio de casos en el sexo femenino (n: 13, 59,1\%) y más de la mitad tenían $>70$ años (Tabla 1). Entre los antecedentes mórbidos destacó la alta frecuencia de diabetes mellitus (n: 8, 36,4\%) y neoplasia maligna actual o precedente (n: 10, 45,5\%). Los pacientes diabéticos estuvieron significativamente asociados a una edad sobre 70 años (OR 12,6; IC95 1,2$133 \mathrm{p}<0,05)$. Cerca de un tercio tenía historia de cuadros de colangitis aguda previa (n: 6) y aproximadamente la mitad (n: 10), hospitalizaciones relacionadas en los últimos tres meses. El antecedente de intervenciones sobre la vía biliar fue frecuente: colecistectomía en $45,5 \%$ de los pacientes (n: 10), incluyendo dos casos con derivación bilio-digestiva y hepatectomía parcial, respectivamente, o antecedentes de colangiografía retrógrada endoscópica (CRE, 40,9\%) o prótesis en la vía biliar (36,4\%). Además, $50 \%$ tenía historia de uso de antibacterianos en los tres meses previos.

La coledocolitiasis fue la causa más frecuente de patología biliar, explicando $45,5 \%$ de los casos; $36,4 \%$ (n: 8) estuvo asociado a cáncer en diferentes niveles (Tabla 1). Un caso se asoció a restos vegetales en un divertículo yuxtapapilar y otro a pancreatitis aguda. El promedio de edad de los pacientes con cáncer (58,8 años), fue significativamente inferior al del resto de los pacientes $(76,7$ años; prueba no paramétrica de Mann-Whitney, $\mathrm{p}<0,01$ ).

\section{Caracterización de los eventos de bacteriemia}

Los 22 pacientes incluidos en esta serie presentaron 26 hospitalizaciones con 29 eventos de bacteriemia. Diecisiete pacientes presentaron un solo episodio (77,3\%), tres pacientes dos episodios cada uno $(13,6 \%)$ y dos pacientes, tres eventos cada uno $(9,1 \%)$, respectivamente. La manifestaciones más frecuentes fueron fiebre y dolor abdominal (> 80\%). Tres cuartos de los pacientes tuvieron ictericia. Sin embargo, la triada de Charcot (fiebre, dolor en hipocondrio derecho e ictericia) estuvo presente en poco más de la mitad de los casos y la péntada de Reynolds (tríada de Charcot junto a compromiso de 
Tabla 1. Características generales en 22 pacientes hospitalizados por colangitis bacteriémica en un hospital general, 2006-2012

\begin{tabular}{lcc}
\hline Variable & \multicolumn{3}{c}{ Resultado } \\
Edad promedio en años (rango) & 70,1 & $(42-95)$ \\
& $n$ & $(\%)$ \\
Edad > 60 años & 16 & $(72,7)$ \\
Edad > 70 años & 12 & $(54,5)$ \\
Género femenino & 13 & $(59,1)$ \\
Consumo de alcohol & 5 & $(27,8)^{*}$ \\
Tabaquismo & 5 & $(27,8)^{*}$ \\
Diabetes mellitus & 8 & $(36,4)$ \\
Cáncer sólido actual o antecedente & 10 & $(45,5)$ \\
Asma/EPOC/fibrosis pulmonar & 4 & $(18,2)$ \\
Cardiopatía & 2 & $(9,1)$ \\
Insuficiencia hepática o cirrosis & 2 & $(9,1)$ \\
Inmunosupresión por corticosteroides & 1 & $(4,5)$ \\
Enfermedad renal crónica o diálisis & 1 & $(4,5)$ \\
Morbilidad & $\mathrm{n}$ & $(\%)$ \\
Colangitis previa & 6 & $(27,3)$ \\
Hospitalización en tres meses previos & 10 & $(45,5)$ \\
Antecedente de intervenciones sobre la vía biliar & $\mathrm{n}$ & $(\%)$ \\
Colecistectomía & 10 & $(45,5)$ \\
Otro tipo de cirugía biliar & 3 & $(13,6)$ \\
Colangiografía retrógrada endoscópica & 9 & $(40,9)$ \\
Prótesis en la vía biliar & 8 & $(36,4)$ \\
Drenaje percutáneo de la vía biliar & 4 & $(18,2)$ \\
Uso de antimicrobianos en los tres meses recientes & 11 & $(50)$ \\
Causa de la patología biliar & $\mathrm{n}$ & $(\%)$ \\
Colédocolitiasis & 10 & $(45,5)$ \\
Cáncer de vía biliar & 3 & $(8,3)$ \\
Cáncer vesicular & 3 & $(13,6)$ \\
Tumor periampular & 1 & $(4,5)$ \\
Cáncer de páncreas & 1 & $(4,5)$ \\
Colangitis esclerosante & 1 & $(4,5)$ \\
Estenosis benigna & 1 & $(4,5)$ \\
Otras causas & 2 & $(9,1)$ \\
Recurrencia de colangitis, con o sin bacteriemia & 7 & $(31,8)$ \\
Mortalidad hospitalaria & 2 & $(9,1)$ \\
*Sobre 18 casos con información disponible. & & \\
& &
\end{tabular}

Tabla 2. Manifestaciones clínicas en eventos de colangitis bacteriémica

\begin{tabular}{|lrc|} 
Variable & Resultado $\mathbf{n / N}$ (\%) \\
Fiebre & $24 / 28$ & $(85,7)$ \\
Dolor abdominal & $23 / 28$ & $(82,1)$ \\
Ictericia & $21 / 27$ & $(77,8)$ \\
Compromiso de conciencia & $6 / 27$ & $(22,1)$ \\
Hipotensión arterial & $20 / 29$ & $(69,0)$ \\
Shock hemodinámico & $9 / 29$ & $(31,0)$ \\
Tríada de Charcot & $15 / 27$ & $(55,6)$ \\
Pentada de Reynolds & $4 / 28$ & $(14,3)$ \\
\hline *con información disponible. & & \\
\hline
\end{tabular}

conciencia y shock) fue inusual (Tabla 2). Dos tercios de los pacientes presentaron hipotensión arterial y cerca de $30 \%$ evolucionó con estado de shock (Tabla 2).

\section{Laboratorio}

Los eventos de bacteriemia se asociaron a recuentos elevados de leucocitos en el hemograma en cerca de la mitad de los casos y con neutrofilia en $65 \%$ (Tabla 3 ). A pesar de que los valores promedio de proteína $\mathrm{C}$ reactiva fueron elevados, sólo 34\% tuvo cifras sobre $100 \mathrm{mg} / \mathrm{L}$. Cerca de la mitad de estos eventos tuvieron cifras elevadas de nitrógeno ureico o valores bajos de albuminemia. La evaluación bioquímica hepática indicó que todos los episodios de colangitis con bacteriemia se asociaron a valores elevados de fosfatasas alcalinas y de gamaglutamil transferasa y la mayor parte con aumento de bilirrubine-

\section{Tabla 3. Manifestaciones de laboratorio en eventos de colangitis bacteriémica}

\section{Variable}

Hemoglobina g/dL

\section{n}

Leucocitos $/ \mathrm{mm}^{3}$ promedio (rango)

$>12.000$ céls $/ \mathrm{mm}^{3}$

$>15.000$ céls $/ \mathrm{mm}^{3}$

Neutrófilos $/ \mathrm{mm}^{3}$ promedio (rango)

$>8.000$ céls $/ \mathrm{mm}^{3}$

VHS mm/hr promedio (rango)

Proteína C reactiva mg/L promedio (rango)

$>100 \mathrm{mg} / \mathrm{L}$

Nitrógeno ureico en sangre $\mathrm{mg} / \mathrm{dL}$ promedio (rango)

$>$ valor normal $20 \mathrm{mg} / \mathrm{dL}$

Glicemia mg/dL

> valor normal $100 \mathrm{mg} / \mathrm{dL}$

$$
\begin{aligned}
& \text { Albuminemia } \mathrm{mg} / \mathrm{dL} \\
& <\text { valor normal } 3,4 \mathrm{mg} / \mathrm{dL}
\end{aligned}
$$

Bilirrubinemia total mg/dL promedio (rango)

> valor normal $1 \mathrm{mg} / \mathrm{dL}$

Fosfatasas alcalinas U/L promedio (rango)

> valor normal $104 \mathrm{U} / \mathrm{L}$

Gama-glutamil transferasa U/L promedio (rango)

$>$ valor normal $39 \mathrm{U} / \mathrm{L}$

Transaminasa glutámico-oxalacética U/L promedio (rango)
$>$ valor normal $35 \mathrm{U} / \mathrm{L}$
$>5$ veces valor normal

Transaminasa glutámico-pirúvica U/L promedio (rango)

> valor normal $31 \mathrm{U} / \mathrm{Ln}$ (\%)

$>5$ veces valor normal

Amilasemia U/L promedio (rango)

$>$ valor normal $100 \mathrm{U} / \mathrm{L}$

Lipasemia U/L promedio (rango)

> valor normal $60 \mathrm{U} / \mathrm{L}$

\section{Resultado}

$12,15(7,6-17)$

$27 \quad 14.077(3.000-44.300)$

$15(55,6 \%)$

$10(37,0 \%)$

$25 \quad 12.468(2.220-42.085)$

$17(65,4 \%)$

$\begin{array}{ll}23 & 49,1(3-115) \\ 26 & 86,9(1,6-307)\end{array}$

$9(34,6 \%)$

$21 \quad 24,7(8-57)$

$11(47,8 \%)$

$24 \quad 136,2(3-297)$

$16(66,7 \%)$

$22 \quad 3,3(2,7-4,2)$

$10(45,5 \%)$

$27 \quad 7,1(0,6-21,3)$

$25(92,6 \%)$

$27 \quad 571(107-1.816)$

$27(100 \%)$

$26 \quad 617(70-2.075)$

$26(100 \%)$

$27 \quad 276,6(35-916)$

$26(96,3 \%)$

$12(44,4 \%)$

$26 \quad 218,3(23-712)$

$25(96,2 \%)$

$12(46,2 \%)$

$18 \quad 324,5(11-2.255)$

$6(33,3 \%)$

$17 \quad 719,1(7-8.571)$

$5(29,4 \%)$ 
mia $(92 \%)$ y transaminasas ( $>95 \%)$, pero en este último caso, sólo $44-46 \%$ tuvo elevaciones $>5$ veces el valor normal (Tabla 3). En contraste, el aumento de amilasemia o lipasemia fue más restringido llegando a 29-33\%. Los valores de fosfatasas alcalinas y bilirrubinemia total o directa fueron significativamente más elevados en los pacientes con cáncer ( 783 vs $403 \mathrm{U} / \mathrm{L}, 11,5$ vs 4,6 mg/ dL y 7,3 vs $3,4 \mathrm{mg} / \mathrm{dL}$, respectivamente, por prueba no paramétrica de Mann-Whitney $\mathrm{p}<0,01$ ).

\section{Manejo}

Aproximadamente, uno de cada cuatro eventos debió ser manejado en la unidad intensiva y cerca de $60 \%$ en unidades de tipo intermedio o intensivo (Tabla 4). El estudio de la vía biliar fue efectuado por ecografía y/o tomografía en la mayor parte de los casos (53-69\%) y en forma más infrecuente por resonancia magnética (23\%). La dilatación de la vía biliar fue detectada en $87 \%$ de los casos y tres eventos no tuvieron este hallazgo, correspondiente a cuadros de bacteriemia asociados a colangitis esclerosante con hepatectomía parcial previa, prótesis in

\begin{tabular}{|c|c|c|}
\hline \multirow{2}{*}{$\begin{array}{l}\text { Variable } \\
\text { Lugar de hospitalización (sobre } 29 \text { eventos de bacteriemia) }\end{array}$} & \multicolumn{2}{|c|}{ Resultado } \\
\hline & $\mathrm{n}$ & $(\%)$ \\
\hline Sala & 12 & $(41,4)$ \\
\hline Unidad de Cuidado Intermedio n (\%) & 10 & $(34,5)$ \\
\hline Unidad de Cuidados Intensivos n (\%) & 7 & $(24,1)$ \\
\hline Subtotal Intermedio e Intensivo & 17 & $(58,6)$ \\
\hline \multicolumn{3}{|l|}{ Estudio (sobre 26 hospitalizaciones) } \\
\hline Ecografía n/N (\%) & $14 / 26$ & $(53,8)$ \\
\hline Tomografía computada n/N (\%) & $18 / 26$ & $(69,2)$ \\
\hline Resonancia magnética n/N (\%) & $6 / 26$ & $(23,1)$ \\
\hline Dilatación de la vía biliar n/N (\%) & $20 / 23$ & $(87,0)$ \\
\hline \multicolumn{3}{|l|}{ Oportunidad de manejo de la patología o complicación $n=26$} \\
\hline Primeras $24 \mathrm{~h}$ & 11 & $(42,3)$ \\
\hline $24-48 h$ & 9 & $(34,6)$ \\
\hline $48-72 \mathrm{~h}$ & 1 & $(3,8)$ \\
\hline$>72 \mathrm{~h}$ & 3 & $(11,5)$ \\
\hline \multicolumn{3}{|l|}{ Intervenciones iniciales sobre la vía biliar o complicaciones } \\
\hline CRE con papilotomía y extracción sin prótesis en la vía biliar & 7 & $(24,1)$ \\
\hline CRE con papilotomía, extracción y prótesis en la vía biliar & 3 & $(10,3)$ \\
\hline CRE con papilotomía y prótesis en la vía biliar & 3 & $(10,3)$ \\
\hline CRE con extracción & 1 & $(3,4)$ \\
\hline CRE con cambio o instalación de prótesis adicional & 7 & $(24,1)$ \\
\hline Colecistectomía, coledocostomía y sonda T & 1 & $(3,4)$ \\
\hline Drenaje percutáneo bajo rayos & 2 & $(6,9)$ \\
\hline Sin intervención sobre la vía biliar & 5 & $(17,2)$ \\
\hline \multicolumn{3}{|l|}{ Estadía hospitalaria } \\
\hline Promedio y rango (días) & 17,8 & $(2-87)$ \\
\hline$\geq 7$ & 21 & $(80,8 \%)$ \\
\hline$\geq 14$ & 10 & $(38,5 \%)$ \\
\hline
\end{tabular}

situ en la vía biliar y coledocolitiasis, respectivamente. En 24 de los 29 eventos de colangitis bacteriémica se efectuaron intervenciones sobre la vía biliar o complicaciones asociadas $(82,8 \%)$. En los cinco casos restantes no se efectuaron intervenciones durante la bacteriemia porque el cuadro estuvo asociado a pancreatitis sin litiasis $(\mathrm{n}=1)$, por la aplicación previa de todo tipo de procedimientos o por la mejoría transitoria en tres pacientes con colangiocarcinoma (n: 3), o por la resolución reciente de la obstrucción de la vía biliar con restos vegetales (n: 1). En los casos que se efectuó una intervención sobre la vía biliar, ésta se realizó en las primeras $72 \mathrm{~h}$ de hospitalización en $80,8 \%$ de las ocasiones, incluyendo el drenaje de un absceso hepático (Tabla 4). En 87,5\% (21 de 24) de las intervenciones sobre la vía biliar o sus complicaciones, se efectuó CRE con diferentes modalidades (Tabla 4). Sólo en 9 de $21(42,9 \%)$ protocolos operatorios disponibles para análisis se encontró pus en la vía biliar al momento de la CRE. Luego del evento bacteriémico, cuatro pacientes fueron sometidos a colecistectomía, uno a derivación bilio-digestiva y otro a pancreato-duodenectomía. La estadía hospitalaria promedio fue de 17,8 días, $80 \%$ estuvo $\geq 7$ días y cerca de $40 \% \geq 14$ días (Tabla 4 ).

\section{Bacteriemias post manipulación de la vía biliar}

Tres eventos fueron observados post manipulación de la vía biliar, dos de ellos en pacientes con cáncer con un intento frustro de descompresión y el otro en una paciente con coledocolitiasis múltiple.

\section{Microbiología}

En 23 de los 29 eventos bacteriémicos se obtuvo un hemocultivo monomicrobiano $(79,3 \%)$ y en $6(20,7 \%)$ uno polimicrobiano. La población total comprende 36 diferentes especies bacterianas (Tabla 5). Las especies mayoritarias fueron bacilos gramnegativos entéricos o no fermentadores ( $>80 \%$ del total) pero cerca de $13 \%$ de las especies correspondió a cocáceas grampositivas (Tabla 5). Entre los bacilos gramnegativos entéricos, la resistencia a cefalosporinas de $3^{\mathrm{a}}$ gen alcanzó al $26,1 \%$ y para las combinaciones con inhibidores de $\beta$-lactamasas fue de 16,7\%. Asimismo, 29,2\% de los aislados de este grupo presentaron resistencia a fluoroquinolonas. Tres especies de bacilos gramnegativos no fermentadores fueron identificados y cuatro dentro de las cocáceas grampositivas, incluyendo Enterococcus gallinarum y Staphylococcus warneri (Tabla 5). La resistencia a quinolonas estuvo significativamente asociada al antecedente de CRE (OR 35; IC95 1,34-911 p < 0,05) o prótesis en la vía biliar (OR 63; IC95 2,08-1.900 p <0,01). Ningún paciente sin estos antecedentes presentó aislados de enterobacterias resistentes a fluoroquinolonas ( $\mathrm{p}<0,05$ por prueba bilateral de Fisher). Por su parte, la resistencia a cefalosporinas de $3^{\text {a }}$ gen estuvo asociada al antecedente de CRE (OR 


\begin{tabular}{|c|c|c|c|}
\hline \multirow[t]{2}{*}{ Especie } & \multicolumn{2}{|c|}{ Frecuencia } & \multirow[t]{2}{*}{ Comentarios sobre susceptibilidad antimicrobiana } \\
\hline & $\mathbf{n}$ & $(\%)$ & \\
\hline \multicolumn{4}{|l|}{ Bacilos gramnegativos entéricos } \\
\hline Escherichia coli & 14 & $(38,9)$ & \multirow{6}{*}{$\begin{array}{l}\text { Resistencia a cefalosporinas de } 3^{a} \mathrm{G} \text { en } 26,1 \% \text {, a combinaciones con inhibidores de } \beta \text {-lactamasas en } \\
16,7 \% \text {. Resistencia a fluoroquinolonas en } 29,2 \% \text { y a amikacina en } 4,2 \% \text { sobre } 24 \text { cepas con información } \\
\text { disponible }\end{array}$} \\
\hline Klebsiella pneumoniae & 8 & $(22,2)$ & \\
\hline Klebiella oxytoca & 1 & $(2,8)$ & \\
\hline Citrobacter sp. & 2 & $(5,6)$ & \\
\hline No especificado & 1 & $(2,8)$ & \\
\hline Subtotal & 26 & $(72,2)$ & \\
\hline \multicolumn{4}{|c|}{$\begin{array}{l}\text { Bacilos gramnegativos no fermentadores y otros } \\
\text { bacilos gramnegativos }\end{array}$} \\
\hline Pseudomonas aeruginosa & 2 & $(5,6)$ & $\begin{array}{l}\text { Resistencia a cefalosporinas 3a G en } 1 \text { caso } \\
\text { Resistencia a carbapenémicos en } 1 \text { caso }\end{array}$ \\
\hline Stenotrophomonas maltophilia & 1 & $(2,8)$ & Susceptible a cotrimoxazol y quinolonas \\
\hline Shewanella sp. & 1 & $(2,8)$ & \\
\hline Aeromonas sp. & 1 & $(2,8)$ & Resistencia a combinaciones con inhibidores de $\beta$-lactamasas y fluoroquinolonas \\
\hline Subtotal & 5 & $(13,9)$ & \\
\hline \multicolumn{4}{|l|}{ Grampositivos } \\
\hline Streptococcus grupo viridans & 2 & $(5,6)$ & Susceptible a penicilina \\
\hline Enterococcus faecalis & 1 & $(2,8)$ & Susceptible a ampicilina \\
\hline Enterococcus gallinarum & 1 & $(2,8)$ & Resistente a vancomicina, susceptible a ampicilina \\
\hline Staphylococcus warneri & 1 & $(2,8)$ & Resistente a oxacilina, susceptible a vancomina \\
\hline Subtotal & 5 & $(13,9)$ & \\
\hline Total & 36 & $(100)$ & \\
\hline
\end{tabular}

16,5; IC95 1,08-250 p < 0,05) y nuevamente, ninguno de los pacientes sin este antecedente, presentó aislados de enterobacterias resistentes a cefalosporinas $(\mathrm{p}<0,05$ por prueba bilateral de Fisher).

\section{Terapia antimicrobiana apropiada en las primeras $24 \boldsymbol{h}$}

En 26 de los 29 eventos se pudo analizar si la terapia fue apropiada en las primeras $24 \mathrm{~h}$ de acuerdo al informe del antibiograma. En 15 de ellos (57,7\%) los esquemas fueron adecuados.

\section{Recurrencia, resultados del tratamiento de los eventos bacteriémicos y condición al alta}

La mayoría de los eventos de bacteriemia tuvo una respuesta inicial favorable (27 de 29; 93,1\%). Un caso con cáncer, catalogado como fracaso $(3,4 \%)$, estuvo asociado a la postergación del manejo de la vía biliar sin respuesta a la terapia antimicrobiana y desarrolló un cuadro de shock séptico con bacteriemia que se resolvió luego de la CRE. Este mismo paciente desarrolló un tercer evento de bacteriemia que tuvo una evolución con deterioro progresivo y falleció durante el manejo de la colangitis y sus complicaciones (n: $1 ; 3,4 \%)$. Siete pacientes $(31,8 \%$ de los 22 analizados) presentaron 11 eventos de recurrencia de los cuadros de colangitis (Tabla 1), correspondientes siete casos a bacteriemia incluidos en esta serie, y los otros cuatro a eventos de colangitis sin bacteriemia. Seis de los siete pacientes $(85,7 \%)$ que presentaron recurrencia con bacteriemia tuvieron una especie microbiana diferente en el segundo o tercer evento, lo que establece una reinfección y no una recaída. El caso restante corresponde a una recaída $(14,3 \%)$. Dos pacientes de la serie fallecieron durante la hospitalización $(9,1 \%)$, correspondiendo a la primera y segunda hospitalización, respectivamente. En un paciente el deceso fue atribuible a la sepsis y en otro, a un cáncer vesicular avanzado (Tabla 1). Los otros 20 pacientes egresaron vivos del primer ingreso (89,9\%). El tiempo transcurrido hasta la primera recurrencia fue corto (Figura 1). La totalidad lo hizo antes de 81 días y el 57\% antes de seis semanas.

\section{Factores asociados a ingreso a UCI, estadía hospitalaria prolongada o recurrencia}

$\mathrm{El}$ ingreso a UCI estuvo significativamente asociado al shock hemodinámico, compromiso de conciencia y la péntada de Reynolds (Tabla 6). En el análisis multivariado, sólo el shock estuvo independientemente asociado al ingreso a UCI. Una estadía igual o superior a dos semanas estuvo asociada significativamente a valores $<100 \mathrm{mg} /$ $\mathrm{dL}$ de glicemia y un valor $>5$ veces de transaminasa glutámico-oxalacética (SGOT) en el análisis univariado, 
Figura 1. Tiempo transcurrido hasta la primera recurrencia de colangitis, con o sin bacteriemia, en 7 pacientes.

Figura 2. Sobrevida desde la fecha de alta del primer egreso en 21 pacientes hospitalizados por colangitis bacteriémica con seguimiento.
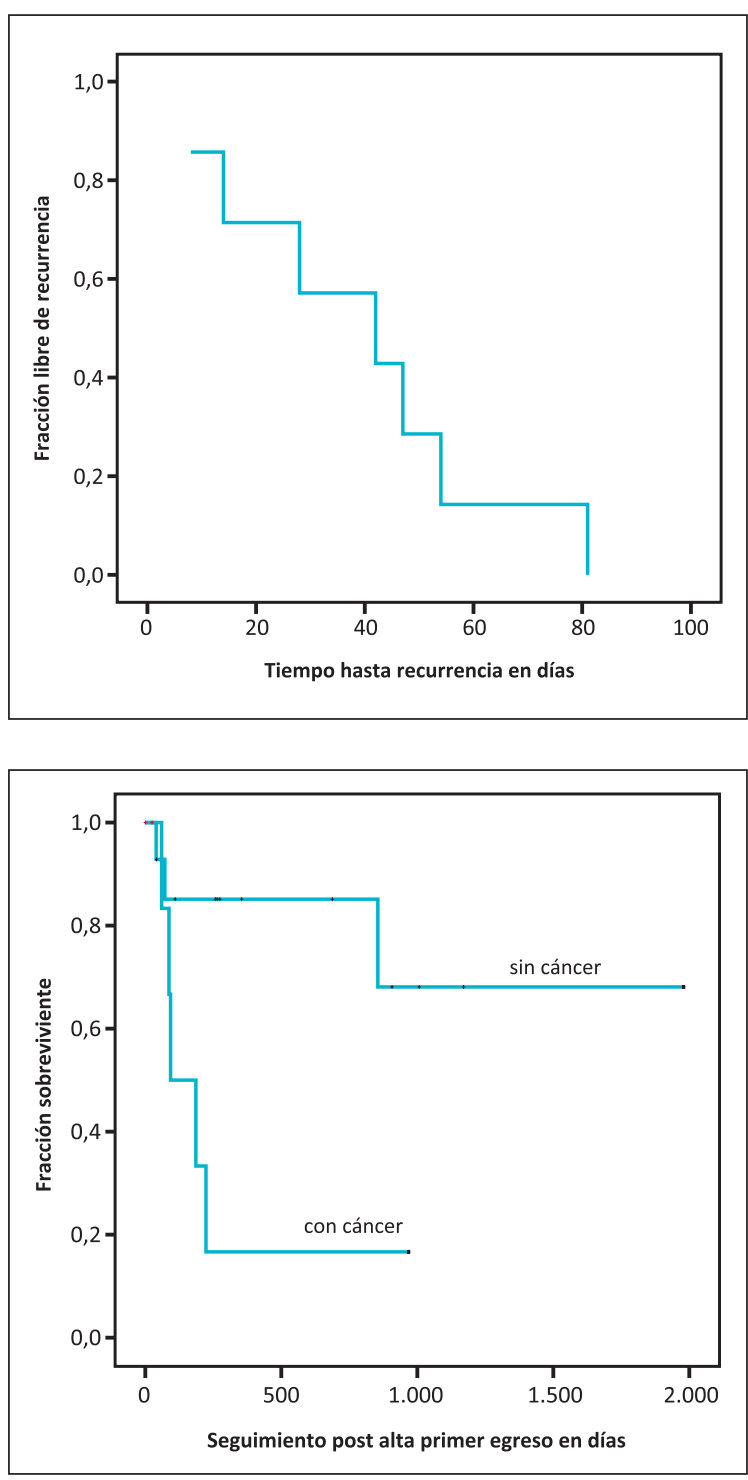

pero sólo a bajos valores de glicemia en el multivariado. Por otra parte, el antecedente de hospitalización en los tres meses recientes fue el único factor asociado al riesgo de recurrencia (Tabla 6).

\section{Sobrevida post primer egreso}

Se pudo determinar la sobrevida en 21 de los 22 pacientes $(40,9 \%)$ luego del primer egreso mediante la búsqueda de certificados de defunción con un promedio de 460 días de seguimiento ( 25 a 1.979), incluyendo seis pacientes egresados con cáncer. En la Figura 2 se muestra la sobrevida desde el alta del primer ingreso de estos 21 pacientes. Se observó una significativa menor sobrevida en los pacientes con cáncer respecto a los pacientes sin cáncer (234 vs 496 días; $\mathrm{p}<0,05$ por prueba log rank para curvas de sobrevida).
Tabla 6. Factores de riesgo asociados a ingreso a UCI, estadía prolongada o a recurrencia de colangitis, con o sin bacteriemia

\begin{tabular}{|c|c|c|c|}
\hline Desenlace & OR & IC95 & $\mathbf{p}$ \\
\hline \multicolumn{4}{|l|}{ Ingreso a UCl } \\
\hline \multicolumn{4}{|l|}{ Análisis univariado } \\
\hline Shock hemodinámico & 38,0 & $3,3-436$ & $<0,001$ \\
\hline Compromiso de conciencia & 19,0 & $2,02-177$ & $<0,01$ \\
\hline Pentada de Reynolds & 20,0 & $1,53-260$ & $<0,01$ \\
\hline \multicolumn{4}{|l|}{ Análisis multivariado } \\
\hline Shock hemodinámico & 30,0 & $2,53-354$ & $<0,01$ \\
\hline \multicolumn{4}{|l|}{ Estadía $\geq 14$ días } \\
\hline \multicolumn{4}{|l|}{ Análisis univariado } \\
\hline Glicemia < 100 mg/dL & 26 & $2,21-304$ & $<0,01$ \\
\hline SGOT > 5 veces normal & 12 & $1,76-81$ & $<0,01$ \\
\hline \multicolumn{4}{|l|}{ Análisis multivariado } \\
\hline Glicemia $<100$ mg/dL & 30 & $2,19-410$ & $<0,05$ \\
\hline \multicolumn{4}{|l|}{ Recurrencia de colangitis } \\
\hline Hospitalización $<3$ meses & 16,5 & $1,5-183$ & 0,01 \\
\hline
\end{tabular}

\section{Discusión}

Varios hallazgos importantes merecen ser destacados en esta serie clínica. Para comenzar, los eventos de colangitis bacteriémica parecen estar asociados a dos poblaciones diferentes. Por una parte, aquellos relacionados a patología litiásica de la vía biliar, caracterizados por una edad promedio mayor, con diabetes mellitus asociada y a una mayor sobrevida a largo plazo, y por otra, la del grupo de pacientes con cáncer en diferentes niveles, más jóvenes, con valores más elevados de fosfatasas alcalinas y billirubinemia y una sobrevida menor a un año. A pesar de que inicialmente parece obvio que los pacientes con cáncer tendrán una sobrevida más corta, ello podría no ocurrir cuando el grupo comparador tiene, en promedio, una edad dos décadas superior como en este caso. Otro aspecto relevante es que la patología neoplásica maligna resultó ser una causa frecuente en el desarrollo de colangitis bacteriémica llegando a explicar un tercio de los casos de esta serie, un hallazgo importante por la baja sobrevida ya comentada y por su estrecha asociación con un fracaso en el tratamiento de colangitis, con o sin bacteriemia ${ }^{2,3}$. Otras publicaciones describen hasta $50 \%$ de fracaso del tratamiento de la bacteriemia en los casos asociados a neoplasia maligna.

Además, se puede destacar que una parte de los eventos de bacteriemia asociados a colangitis emerge en pacientes con antecedentes de infección anterior de la vía biliar, hospitalizaciones, intervenciones sobre ella, o uso previo de antimicrobianos y con un riesgo de recurrencia no despreciable. Estos datos son relevantes ya que, como se comprobó en esta casuística, determinan un mayor 
riesgo de resistencia antimicrobiana ante quinolonas o cefalosporinas de $3^{\text {a }}$ gen, compuestos importantes en el manejo inicial de estos cuadros, y porque como además se observó en algunos casos de CRE, pueden provocar eventos de bacteriemia. Asimismo, abren la puerta para considerar esquemas de antibioprofilaxis luego del primer evento y que parecen ser necesarios durante los primeros dos a tres meses. La profilaxis antibacteriana con ciprofloxacina ha demostrado disminuir los eventos de colangitis en pacientes con cáncer en los que se instala la primera prótesis en la vía biliar respecto a placebo pero no se ha evaluado su rol para prevenir nuevos eventos de colangitis en pacientes ya afectados con este problema ${ }^{4}$. Sin embargo, otros estudios no han demostrado eficacia, incluyendo una revisión sistemática publicada el 2002, antes del trabajo citado más arriba ${ }^{5-7}$. En nuestra experiencia, el único factor de riesgo para considerar tal aproximación fue el antecedente de hospitalización reciente. Por otra parte, que tres de los eventos registrados hayan ocurrido luego de la manipulación endoscópica de la vía biliar, respalda el uso de profilaxis antibacteriana, especialmente en aquellos casos donde se anticipa una resolución difícil por neoplasia o litiasis múltiple, tal como ha sido demostrado en un meta-análisis donde los eventos de bacteriemia disminuyeron significativamente ${ }^{8}$.

Los resultados de esta casuística indican también que las manifestaciones clínicas clásicas como la triada de Charcot y la péntada de Reynolds no fueron predominantes y parece ser más relevante, la presencia de shock hemodinámico lo que determina el ingreso a UCI, un fenómeno presente en un tercio de los casos de bacteriemia.

Asimismo, esta serie comprueba cómo la intervención activa y precoz sobre la vía biliar para controlar la obstrucción se ha convertido en la estrategia de manejo predominante en pacientes con colangitis luego de que se demostrara hace ya dos décadas que la mortalidad se reduce drásticamente en comparación a la cirugía abierta. Es probable que la intervención precoz observada en nuestro centro haya incidido en una alta tasa de respuesta clínica favorable ( $>90 \%$ de los casos), a pesar de que la terapia antimicrobiana no fue óptima en más de $40 \%$ de los eventos en las primeras horas de la bacteriemia 9 . En nuestro país se han obtenido similares resultados en experiencias publicadas confirmando la alta tasa de éxitos con una baja mortalidad asociada ${ }^{10}$. En grandes series, el fracaso terapéutico ha estado asociado a una causa maligna de obstrucción, mayores concentraciones de bilirrubinemia, a la presencia de Candida o bacterias pan-resistentes en los cultivos de bilis y a la presencia de bacteriemia $^{3}$. De la misma manera, la baja tasa de mortalidad observada en esta serie es similar a otras experiencias publicadas en Chile o en otros países ${ }^{3,11,12}$ y que informan también de un bajo número de complicaciones y estadía hospitalaria en pacientes con colangitis sin bacteriemia, siendo estos rasgos resultado de una optimización de la terapia de soporte y la descompresión precoz de la vía biliar como ya fue comentado.

En nuestra serie, los eventos de colangitis bacteriémica se asociaron a una diversidad de agentes etiológicos, en $20 \%$ con cultivos polimicrobianos, con predominio de bacilos gramnegativos entéricos tal como ha sido descrito en la literatura médica ${ }^{2,3} \mathrm{y}$ en ocasiones por agentes inusuales como Aeromonas sp, Shewanella sp. o S. warneri. Estos tres microorganismos han sido infrecuentemente descritos en pacientes con patología de la vía biliar. En el caso de Shewanella sp, su presencia en esta serie representa uno de los escasos reportes en el mundo en este escenario ya que suele observarse en cuadros de otitis o de infecciones de piel y tejidos blandos ${ }^{13}$. El caso de $S$. warneri, una especie del grupo de Staphylococcus coagulasa negativa, también representa una excepción ya que ha sido descrito como agente de infección asociada a cuerpos extraños, como agente de endocarditis o espondilodiscitis y en pacientes inmunosuprimidos ${ }^{14,15}$. No tenemos conocimiento de que haya sido descrito previamente en asociación con cuadros de colangitis o bacteriemia de foco biliar. El tercer microorganismo, Aeromonas sp, es un integrante más conocido en las infecciones asociadas a la vía biliar ${ }^{3,16-19}$.

Finalmente, la estadía hospitalaria en esta serie fue prolongada, siendo $\geq 7$ días en $80 \%$ de los casos $\mathrm{y} \geq 2$ semanas en un tercio aproximadamente, lo que subraya la morbilidad prolongada de los cuadros de colangitis bacteriémica. Estas cifras son notoriamente superiores a lo descrito por Felmer y cols., en un grupo de 70 pacientes en Valdivia tratados con CRE (3,5 días promedio desde la CRE) y parecen ser explicadas por la existencia de pacientes con bacteriemia y shock y por la mayor frecuencia de pacientes con cáncer en nuestra serie ${ }^{10}$. La estadía $\geq$ dos semanas estuvo asociada en el análisis univariado a bajos valores de glicemia y aumento $>5$ veces en los valores de SGOT, elementos que sugieren que la injuria hepática puede estar ligada a mayores estadías hospitalarias. Sin embargo, no fue posible demostrar también una conexión con tiempos prolongados de protrombina, albuminemia o bilirrubinemia (datos no mostrados). En el análisis multivariado, sólo la glicemia $<100 \mathrm{mg} / \mathrm{dL}$ presentó una asociación significativa con estadía prolongada.

Este trabajo tiene varias limitaciones entre las que se cuentan su bajo poder estadístico para explorar más asociaciones o factores de riesgo y su diseño descriptivo, retrospectivo, no comparativo, que impide analizar por ejemplo diferentes desenlaces entre pacientes con y sin bacteriemia. No se encontraron más casos de bacteriemias asociadas a colangitis a pesar de utilizar una ventana de varios años de estudio y de utilizar dos estrategias para captar casos: diagnósticos de egresos y registro personal de uno de los autores. Es probable que hayan ocurrido más casos en el período analizado que no pudieron de 
esta manera ser contabilizados en esta experiencia. Parte de la limitación estadística del trabajo se ve reflejada en los valores OR elevados y los amplios intervalos de confianza encontrados en los análisis multivariados, los que requieren mayores estudios. Publicaciones previas han señalado que los pacientes con bacteriemia de origen biliar tienen un mejor pronóstico a 30 días desde el ingreso que los pacientes con bacteriemia de otro origen, pero en el subgrupo de origen biliar, la bacteriemia asociada a patología neoplásica maligna tiene un peor pronóstico que otras causas de bacteriemia originada en la vía biliar. ${ }^{3}$ Debido a la falta de solicitud de cultivos, esta casuística tampoco incluyó la posibilidad de identificar especies anaerobias estrictas y no permitió evaluar la relevancia de los resultados del cultivo de la vía biliar ya que rara vez fue solicitado. Evaluaciones cuantitativas del cultivo de la vía biliar no han encontrado relevancia alguna para predecir complicaciones en estos pacientes ${ }^{20}$. No obstante, a pesar de sus limitaciones, da cuenta de la microbiología y estrategias actuales de manejo y permitió definir algunos factores de riesgo asociados al ingreso a UCI o recurrencia así como estimar la sobrevida de pacientes, con o sin cáncer, a largo plazo.

En resumen, esta serie clínica ha aportado información sobre la morbilidad prolongada y riesgo de ingreso a UCI que tienen los cuadros de colangitis aguda bacteriémica, sobre la importancia de la resolución precoz de la obstrucción de la vía biliar a pesar de una cobertura antimicrobiana inadecuada, el patrón recurrente frecuente, su asociación con una diversidad de especies bacterianas, algunas de ellas altamente inusuales y la importancia de la etiología neoplásica en el pronóstico post bacteriemia.

\section{Resumen}

Introducción: La información sobre los cuadros de colangitis aguda bacteriémica es fragmentaria en Chile. Objetivo: Analizar las características clínicas, evolución, microbiología y factores de riesgo asociados a ingreso a UCI, recurrencia y resistencia antimicrobiana. Pacientes y Métodos: Estudio retrospectivo descriptivo con adultos atendidos entre el 2006 y el 2012 en un hospital general. Resultados: Se identificaron 22 pacientes con 29 episodios de bacteriemia. Un 27,3\% tenía historia previa de colangitis aguda, $45,5 \%$ de hospitalizaciones en los últimos tres meses y $50 \%$ recibió previamente antimicrobianos. La coledocolitiasis fue la causa más frecuente de obstrucción $(45,5 \%)$ y las neoplasias ocuparon el segundo lugar (36,4\%). El 31\% desarrolló shock hemodinámico y fue el factor determinante para ingresar a la UCI (OR 30, p < 0,01) En 24 de los 29 eventos de colangitis bacteriémica se efectuaron intervenciones sobre la vía biliar (VB) o complicaciones asociadas (82,8\%), las que se realizaron predominantemente en las primeras 72 h de hospitalización (80,8\%). Las especies bacterianas mayoritarias fueron bacilos gramnegativos entéricos o no fermentadores ( $>80 \%$ del total) y se observaron agentes inusuales como Staphylococcus warneri, Shewanella spp y Aeromonas spp. Entre los bacilos gramnegativos entéricos, 29,2\% presentó resistencia a fluoroquinolonas y $26,1 \%$ a cefalosporinas de tercera generación, fenómenos asociados al antecedente de colangiografía endoscópica retrógrada (OR 35 y 16,5 respectivamente, $\mathrm{p}<0,05$ ). El $93,1 \%$ de los eventos de bacteriemia tuvo una respuesta favorable pero $31,8 \%$ de los pacientes presentó recurrencia de colangitis, con o sin bacteriemia, un hecho asociado a hospitalización reciente $(\mathrm{OR} 16,5, \mathrm{p}=0,01)$ y que se dio en todos los casos antes de 81 días. Dos pacientes con cáncer fallecieron en la misma hospitalización $(9,1 \%)$, aunque uno solo de ellos en forma atribuible a la infección. La estadía hospitalaria promedio fue de 17,8 días. Conclusiones: Con la intervención precoz sobre la $\mathrm{VB}$, los cuadros de colangitis bacteriémica han logrado una baja letalidad pero usan recursos intensivos, tienen una estadía prolongada, un patrón recurrente, pueden estar asociados a cáncer y a una diversidad de agentes bacterianos, algunos de ellos resistentes.

\section{Referencias bibliográficas}

1.- Hanau L H, Steigbigel N H. Acute (ascending) cholangitis. Infect Dis Clin North Am 2000; 14: 521-46.

2.- Lee C C, Chang I J, Lai Y C, Chen S Y, Chen S C. Epidemiology and prognostic determinants of patients with bacteremic cholecystitis or cholangitis. Am J Gastroenterol 2007; 102: 563-9.

3.- Thompson J, Bennion R S, Pitt H A. An analysis of infectious failures in acute cholangitis. HBP Surgery 1994; 8: 139-45.

4.- Chan G, Barkun J, Barkun AN, Valois E, Cohen A, Friedman G, et al. The role of ciprofloxacin in prolonging polyethylene biliary stent patency: a multicenter, double-blinded effectiveness study. J Gastrointest Surg 2005; 9: 481-8.

5.- Sung J J Y, Sollano J D, Lai C W, Ismael A, Yung M Y, Tumala I, et al. Long-term ciprofloxacin treatment for the prevention of biliary stent blockage: a prospective randomized study. Am J Gastroenterol 1999; 94: 3197-201.

6.- Luman W, Ghosh S, Palmer K R. A combination of ciprofloxacin and Rowachol does not prevent biliary stent occlusion. Gastrointest Endosc 1999; 49 (3 Pt 1): 316-21.
7.- Galandi D, Schwarzer G, Bassler D, Allgaier H P. Ursodeoxycholic acid and/ or antibiotics for prevention of biliary stent occlusion. Cochrane Database Syst Rev 2002; (3): CD003043.

8.- Brand M, Bizos D, O’Farrell P Jr. Antibiotic prophylaxis for patients undergoing elective endoscopic retrograde cholangiopancreatography. Cochrane Database Syst Rev 2010; (10): CD007345.

9.- Lai E, Mok F,Tan E, Lo C, Fan S, You K, et al. Endoscopic biliary drainage for severe acute cholangitis. N Engl J Med 1992; 326: 1582-6.

10.- Felmer O, Vásquez J, Yusef P, Alliende M, C 
Cárcamo C. Resultados del drenaje endoscópico de la vía biliar en el tratamiento de la colangitis aguda. Cuadernos Cirugía 2006; 20: 16-20.

11.- Anselmi M, Salgado J, Arancibia A. Colangitis aguda debido a coledocolitiasis: ¿Cirugía tradicional o drenaje biliar endoscópico? Rev Med Chile 2001; 129: 753-62.

12.- Losada H, Manterola C, Vial M, Pineda V. Sepsis de origen biliar ¿Alternativa diagnóstica en pacientes con colangitis aguda de origen litiásico? Rev Chil Cir 2004; 56: 562-6.

13.- Holt H M, Gahrn-Hansen B, Bruun B Shewanella algae and Shewanella putrefaciens: clinical and microbiological characteristics. Clin Microbiol Infect 2005; 11: 347-52.

14.- Wood C A. Significant infections caused by
Staphylococcus warneri. J Clin Microbiol 1992; 30: 2216-7.

15.- Kamath U, Singer C, Isenberg H D. Clinical significance of Staphylococcus warneri bacteremia. J Clin Microbiol 1992; 30: 261-4.

16.- Chuang H C, Ho Y H, Lay C J, Wang L S, Tsai Y S, Tsai C C. Different clinical characteristic among Aeromonas hydrophila, Aeromonas veronii biovar sobria and Aeromonas caviae monomicrobial bacteremia. J Korean Med Sci 2011; 26: 1415-20.

17.- Mencacci A, Cenci E, Mazolla R, Farinelli S, D'Alò F, Vitali M, et al. Aeromonas veronii biovar veronii septicaemia and acute suppurative cholangitis in a patient with hepatitis B. J Med Microbiol 2003; 52:
727-30.

18.- Clark N M, Chenoweth C E. Aeromonas infection of the hepatobiliary system: report of 15 cases and review of the literature. Clin Infect Dis 2003; 37: 506-13.

19.- Tena D, González-Praeotorius A, Gimeno C, Pérez-Pomata M T, Bisquert J. Infección extraintestinal por Aeromonas spp.: revisión de 38 casos. Enf Infecc Microbiol Clin 2007; 25: 235-41.

20.- Losada H, Manterola C, Pineda V, Vialg, Avendaño L. Asociación entre recuento bacteriano en la bilis y desarrollo de morbilidad postoperatoria en pacientes con colangitis aguda. Rev Chil Cirugía 2009; 61: 142-47. 